mother liquor they shrink visibly in the direction of the $c$ axis, and the birefringence falls to less than 0.001 . This shrinkage is accurately determined by the X-ray measurements which were carried out both on the air-dried crystals and on crystals mounted in their mother liquor. For the wet crystals $a=b=$ $63.5 \mathrm{~A} ., c=145 \mathrm{~A}$. ; for the dry crystals $a=b=$ $59 \mathrm{~A} ., c=105 \mathrm{~A}$. The space group in the case of the wet crystals is $P 2_{1} 2_{1} 2_{1}$, showing, in X-ray intensities as in dimensions, a close approach to the tetragonal space group $P 4_{2} 2_{1}$, whence there are probably 8 molecules in the unit cell. There were too few X-ray reflections from the dry crystals to indicate the space group, but it seems most probable that this unit cell also contains eight molecules, but without water of erystallization. viously measured, pepsin and insulin, and with hæmoglobin and chymotrypsin (recorded below). The similarity in cell dimensions extends also to the types of photographs obtained from wet and dry crystals of lactoglobulin. The wet tabular crystals give very beautiful $\mathrm{X}$-ray pictures with reflections covering the whole field and extending out to spacings of less than $2 \cdot 4 \mathrm{~A}$. Those from the needle crystals are less good owing to their much smaller size. But with the dry crystals the photographs are very poor indeed, and this is evidently due to the poor orientation of the protein molecules in the collapsed structure. There are no X-ray reflections with spacings less than $20 \mathrm{~A}$. The sharpness of the limit is reminiscent of that already observed on the much better X-ray photographs obtained from air-dried insulin ${ }^{4}$, and

\begin{tabular}{|c|c|c|c|c|c|c|c|c|}
\hline & & Pepsin & Hæmoglobin & Chymotrypsin & $\begin{array}{l}\text { Lactoglobulin } \\
\text { tabular }\end{array}$ & $\begin{array}{l}\text { Lactoglobulin } \\
\text { needle }\end{array}$ & Insulin & $\begin{array}{l}\text { Tobacco seed } \\
\text { globulin }\end{array}$ \\
\hline Wet & \begin{tabular}{l}
\multicolumn{1}{c}{$a$} \\
$b$ \\
Layer-spacing \\
Molecular volume $\left(\mathbf{A}^{3}\right)$
\end{tabular} & $\begin{array}{c}116 \\
67 \\
9 \times 51 \cdot 2 \\
67,000\end{array}$ & $\begin{array}{l}109 \\
63 \cdot 2 \\
50 \cdot 2 \\
174,000\end{array}$ & $\begin{array}{l}\frac{1}{2} \times 99 \\
67 \cdot 8 \\
65 \\
55,000\end{array}$ & $\begin{array}{c}63 \cdot 5 \\
63 \cdot 5 \\
2 \times 72 \cdot 5 \\
73,000\end{array}$ & $\begin{array}{l}63 \cdot 5 \\
63 \cdot 5 \\
2 \times 62 \cdot 5 \\
63,000\end{array}$ & & \\
\hline Dry & 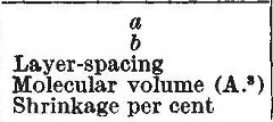 & & $\begin{array}{c}102 \\
56 \\
35 \\
101,000 \\
42\end{array}$ & $\begin{array}{l}45 \\
62 \cdot 5 \\
53 \cdot 5 \\
38,000 \\
31\end{array}$ & $\begin{array}{l}59 \\
59 \\
2 \times 52 \cdot 5 \\
46,000 \\
37\end{array}$ & $\begin{array}{l}54 \\
54 \\
2 \times 62 \cdot 5 \\
46,000 \\
27\end{array}$ & $\begin{array}{l}130 \\
74 \cdot 7 \\
30 \cdot 6 \\
50,000\end{array}$ & $\begin{array}{c}2 \times 61 \\
2 \times 61 \\
2 \times 61 \\
455,000\end{array}$ \\
\hline
\end{tabular}

The wet needle crystals occupy a place intermediate between the wet and dry tabular crystals. They appear to be exactly tetragonal, elongated along $c$. The cell dimensions are $a=b=63 \cdot 5 \mathrm{~A}$., $c=125 \mathrm{~A}$., space group $P 4_{9} 2_{1}$. The fact that the needles show positive birefringence suggests that they differ from the tabular form in the orientation of the molecules as well as in water content, and this is confirmed by the drying phenomena. There is little apparent change in shape or birefringence on exposure of the needles to air, but the very weak X-ray diffraction effects obtained from the dried crystals indicate a new unit cell with approximately $a=b=54 \mathrm{~A}$., and $c=125 \mathrm{~A}$.

The unit cell dimensions of the different lacto. globulin crystals suggest that in each case there are eight protein molecules in the cell, associated with different quantities of water of crystallization. Some difficulty was experienced, however, in making measurements of the crystal density to check this, owing to the great solubility of the protein crystals in salt solutions. "A value of $1 \cdot 257$ was obtained in sugar solutions for the density of the wet tabular crystals, and this may be regarded as an upper limit for the density ( $c f$. Adair and Adair ${ }^{2}$ ). It is in agreement with the presence of a considerable proportion of water in the crystals. It has so far proved impossible to measure the density of the needle crystals in any solvent, since even in sugar solutions the crystals rapidly imbibe liquid, with resultant swelling and loss of shape. The density of the dry tabular crystals in 0 -dichlorbenzene and toluene was found to be 1.27 , which is lower than might be expected, probably owing to the occlusion of air in the irregular structure formed in the drying process. The molecular weight of the protein if calculated from this value and the cell dimensions given above is 35,300 , or assuming the more probable density of $1 \cdot 31$ (that of dried insulin) 36,500 . These values are in agreement with that obtained by ultracentrifuge measurements-about $39,000^{3}$, within the limits of experimental accuracy.

It is of most interest to compare the crystal structure of these protein crystals with those pre- suggests that in the insulin crystals also a certain degree of molecular disorientation prevails. As might be expected the crystal structure of dry insulin is of a very compact type, while in the wet lactoglobulin crystals, as in pepsin, the molecular arrangement must be loose and extended.

\section{Molecular Weight of a Tobacco Seed Globulin}

By Dr. Dorothy Crowfoot, Dept. of Mineralogy, Oxford, and Dr. I. Fankuchen, Crystallographic Laboratory, Cambridge

In order to determine the structure of protein crystals from X-ray diffraction effects it is usually necessary to measure fairly large single crystals. An exception to this rule is the case of crystals belonging to the cubic system, for which powder photographs should provide sufficient data. A preparation of a cubic tobacco seed globulin isolated by H. S. Vickery of the Rockefeller Institute, New York, was given to us by Dr. D. M. Wrinch, and this we have examined by the X-ray method in the form of the dry powder.* The crystals were very small but well-formed isotropic octahedra.

Three powder lines were recorded on the X-ray photographs which correspond in spacing to the first three reflections from a cubic face centred lattice of dimensions $a=123 \mathrm{~A}$. This value permits us to calculate the maximum molecular weight of the asymmetric unit as 363,000 , accepting the presence of only the four molecules in the unit cell required by the symmetry, and the density of $1 \cdot 287 \pm 0 \cdot 001$, measured in a sodium phosphate buffer at $p \mathrm{H} 5 \cdot 0$. Since the crystals lose 10.4 per cent of their weight when dried in a vacuum at $100^{\circ}$ due to loss of what may be considered water of crystallization, the maximum molecular weight of the dried protein may be calculated as 325,000 . This molecular weight is in agreement in order of magnitude with the sedimentation constant of $12.7 \times 10^{-13}$ found for the same protein by $J$. Philpot in the Department of

*W. T. Astbury ${ }^{5}$ has previously measured the large angle scattering. 
Biochemistry, Oxford, and is similar to those of other seed globulins, excelsin and edestin given by Svedberg as about $300,000^{8}$. The X-ray measurements provide some additional evidence to show that the units present in these proteins are of very considerable size, although at this stage we cannot exclude the possibility that the true chemical molecular weight of the tobacco seed globulin is a sub-multiple of 325,000 .

\section{An X-Ray Study of Chymotrypsin aNd HAMOGLOBIN}

By Prof. J. D. Bernal, F.R.S., Dr. I. Fankuchen and Max Perutz, Crystallographic Laboratory, Cambridge

We have recently been fortunate in obtaining well-developed crystals of two proteins-chymotrypsin and hæmoglobin. The former were prepared for us by Dr. Northrop of Princeton and the latter -methæmoglobin of horse-by Dr. Adair at the Physiological Laboratories, Cambridge. In both cases the crystals were well formed and large ( $\frac{1}{2} \mathrm{~mm}$.) and well suited for X-ray analysis.

Chymotrypsin crystallizes in thick diamond-shaped plates at first thought to be orthorhombic but afterwards discovered to be monoclinic twins. It was examined both in the native state in its mother liquor and dried. The cell dimensions are $a=49 \cdot 6 \mathrm{~A}$, $b=67.8 \mathrm{~A}$., $c=66.5 \mathrm{~A}$., $\beta=102^{\circ}$ for the wet crystals, and $a=45 \mathrm{~A} ., b=62.5 \mathrm{~A} ., c=57.5 \mathrm{~A} ., \beta=$ $112^{\circ}$ for the dry. The space group in both cases is probably $P 2_{1}$. The cell volumes are 219,000 and $151,000 \mathrm{A.}^{3}$ respectively. It is evident that very considerable shrinkage takes place on drying, nearly all of which is in the direction of the $c$ axis. The density of the wet crystals could be measured by the methods of Adair and was found to be $1 \cdot 277$. If we assumed four molecules per cell this would give a molecular weight including water of crystallization of 42,300 . In the case of the dry crystals it was unfortunately impossible to measure the density on account of the difficulty of removing crystallized salts. Assuming the density of the dried protein to be the same as that of dry insulin, namely, $1 \cdot 31$, the molecular weight is 32,000 . This value for the molecular weight of a protein seems rather lower than is usually obtained by the centrifuge method, which, however, has not as yet been applied to chymotrypsin. It is difficult without a deeper analysis to say much about the inner structure of the crystals, but the extreme strength of (001) indicates a layer structure, while the weakness of ( $h o l$ ) when $h$ is odd points to a pseudo-glide plane parallel to $(010)$.

The hæmoglobin crystals were found to be monoclinic and usually twinned, corresponding very closely to the description given by Reichert and Brown ${ }^{8}$. The dimensions are $a=109 \mathrm{~A}, \quad b=63 \cdot 2 \mathrm{~A}$, $c=$ $54 \cdot 2 \mathrm{~A} ., \beta=112^{\circ}$ for the wet crystals and $a=102 \mathrm{~A}$., $b=56 \mathrm{~A} ., c=49 \mathrm{~A}$., $\beta=134^{\circ}$ for the dry. The space group in both cases is $C 2$ with a face-centred pseudohexagonal cell. The cell volumes are 348,000 and 202,000 respectively. Here the shrinkage takes place apparently more by the increase of the $\beta$ angle rather than by the shortening of cell edges. The density of the wet crystals is $1 \cdot 242$, which gives a molecular weight of protein and water on the assumption of two molecules per cell of 131,000 . The molecular weight of the dry crystals has not been determined on account of the salt content, but taking the value

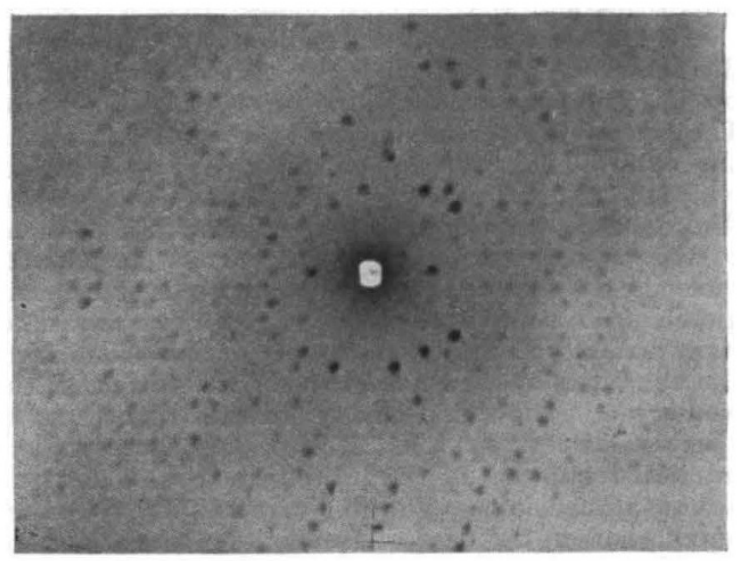

Fig. 1.

WET HAMOGLOBIN CRYSTAL; $5^{\circ}$ OSCILLATION ABODT $b$-AXIS SHOWING ( $h k o$ )-ZONE AT CENTRE OF PHOTOGRAPH. NOTE THE PSEUDO-HEXAgONAL CHARACTER OF THE PATTERN AND THE INTENSITY OF THE REFLECTIONS AT HIGH ANGLES.

of $1 \cdot 26$ based on that measured by Chick and Martin for the closely similar serum albumin, the molecular weight is 77,000. The air-dried crystals still contain water. Taking the amount estimated by Haurowitz ${ }^{10}$ as 9.6 per cent, the molecular weight of the dry protein becomes 69,000 , which agrees excellently with the 67,000 found by chemical methods.

The molecular arrangement appears to be based on a layer lattice with a puckered pseudo-hexagonal network. In the dry crystals it is possible to arrive at a structure which accounts qualitatively for the

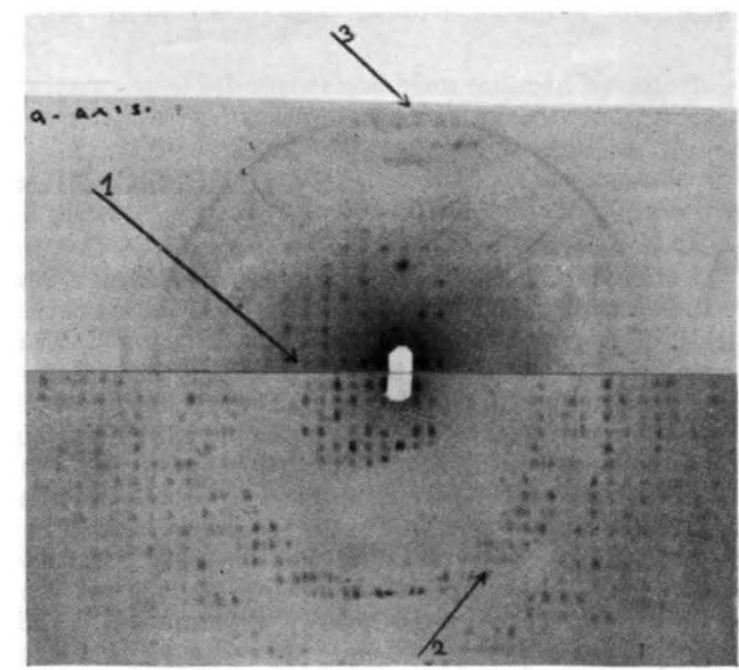

Fig. 2.

COMPARISON PHOTOGRAPH OF CHYMOTRYPSIN : WET BELOW AND DRY ABOVE; $5^{\circ}$ OSCIILATION ABOUT $b$-AXIS SHOWING AT CENTRE OF PHOTOGRAPH THE (okl)-ZONE. NOTE LARGE DIFFERENCE OF SPACING OF (00l)-REFLECTIONS $\left(\uparrow_{1}\right)$ AND COMPARATIVELY SMALL DIFFERENCE OF LAYER-LiNe separation. The Wet crystal Was a TWIN; THE (l $k l)$-REFLECTIONS SHOW DOUBLING OF SPOTS $(\uparrow$, ). THE RAPID FALLING OFF OF INTENSITY IN THE DRY CRYSTAL PHOTOGRAPHS SHOULD BE NOTED. THERE IS ALSO THE APPEARANCE OF WEAK SPOTS AT A LARGER ANGLE, CORRESPONDING TO A SPACING OF 5 A. $(\uparrow 8)$ 